\title{
Evaluación del conocimiento de mitos y verdades sobre sobre arácnidos en Argentina y su posible incidencia en salud
}

\author{
I ' Sergio Gustavo Rodríguez Gil, 2 Cristina Luisa Scioscia, ${ }^{3}$ Luis Giambelluca, \\ ${ }^{4}$ Guillermo Reboredo, ${ }^{5}$ Alda Gonzalez I
}

Resumen: Los arácnidos son un grupo megadiverso, en el cuál están las arañas y los escorpiones. Si bien todas las especies de ambos grupos tienen veneno, solo algunas son peligrosas para el ser humano, pudiendo causar hasta la muerte, y ocupan un lugar importante en las tradiciones de muchos pueblos. El objetivo del presente trabajo es conocer, mediante una encuesta, cuáles son los conocimientos de las personas sobre arañas y escorpiones y poner a prueba mitos y verdades mediante preguntas y repreguntas. Los resultados muestran un desconocimiento considerable en la población participante, especialmente con avanzado nivel educativo, que aceptan mitos por encima de los descubrimientos científicos verdaderos; además la respuesta entre varones y mujeres difiere de manera significativa en muchas preguntas. Estos resultados obligan a pensar políticas de educación que reviertan esos conocimientos erróneos basados en prejuicios o información de dudosa veracidad, por aquellos basados en la evidencia científica. Esto permitiría un manejo racional de estos grupos y así brindar medidas de prevención eficientes y pautas de acción si ocurriese un accidente.

> Palabras clave: araneismo; escorpionismo; conocimiento; salud.

\author{
' CEPAVE, Laboratorio de \\ Aracnología. La Plata, Argentina \\ (sergiorodriguezgil@cepave. \\ edu.ar). \\ ORCID: 0000-0003-4608-1961 \\ ${ }^{2}$ Museo Argentino de Ciencias \\ Naturales Bernardino Rivadavia, \\ División Aracnología. Buenos \\ Aires, Argentina (crisscio@yahoo. \\ com.ar). \\ ORCID: 0000-0002-1103-9125 \\ ${ }^{3}$ CEPAVE, Laboratorio de \\ Aracnología. La Plata, Argentina \\ (giambelluca@cepave.edu.ar). \\ ORCID: 0000-0001-6530-8143 \\ ${ }^{4}$ CEPAVE, Laboratorio de \\ Aracnología. La Plata, Argentina \\ (grreboredo@yahoo.com.ar). \\ ORCID: 0000-0002-1214-316x \\ ${ }^{5}$ CEPAVE, Laboratorio de \\ Aracnología. La Plata, Argentina \\ (asgonzalez@cepave.edu.ar). \\ ORCID: 0000-0002-2089-0907
}

Recebido em: 29/05/2019 Aprovado em: 30/07/2019 Revisado em: 28/03/2020 


\section{Introducción}

Los arácnidos son un grupo de animales considerado megadiverso, con más de 50.000 especies solo entre arañas y escorpiones (WORLD SPIDER CATALOG, 2019; OVE REIN, 2019). Esta gran diversidad de formas está acompañada de una gran distribución espacial, con algunas especies cosmopolitas, y se encuentran hasta en islas remotas o en altamar, como lo observado por el naturalista Charles Darwin, quien vio una amplia dispersión de arańas por efecto del viento al pasar por las costas de Sudamérica, lo cual hizo que el mítico buque Beagle fuera literalmente invadido por ellas (DARWIN, 1913).

Además de arañas y escorpiones existen otros grupos de arácnidos como los ácaros, opiliones, pseudoescorpiones y un poco menos conocidos, los amblipígidos, ricinúlidos, solífugos, uropigios, palpígrados y esquizómidos (BLANCO VARGAS; SALAS LÓPEZ, 2007).

De todos los arácnidos, arañas y escorpiones ocupan un lugar preponderante dentro del saber popular. Ambos grupos tienen una cualidad que los hace distintivos dentro de los arácnidos y es que algunas pocas especies son peligrosas para el ser humano y sus mascotas, pudiendo en casos extremos causar la muerte o un daño irreversible por su veneno, o un gran dolor a causa de las picaduras. Este atributo los coloca en un lugar destacado en las tradiciones de muchos pueblos, los cuales los han visto como dioses o demonios (DE LA COLINA, 2012; VÍQUEZ, 2003; HOFFMAN, 1993; FERNÁNDEZ RUBIO, 2018). Las arañas también han sido reconocidas por tejer tela (BLACKLEDGE, 2013).

Por lo antedicho las arańas y los escorpiones han sido incluidos en muchos relatos y muchas creencias, que sin respaldo científico fueron tomando fuerza en el conocimiento colectivo y pasando a ser parte del acervo propio de cada cultura. Las arañas en Grecia, eran ejemplo de trabajadoras por la habilidad para tejer telas. En India, las arañas y sus telas fueron consideradas símbolo del centro del universo. Las arañas causan tanta intriga que, en los medios de comunicación por ejemplo, suelen aparecer preguntas acerca de situaciones extremas sobre ellas, a tal punto que dio origen a un artículo científico sobre los "records" alcanzados por las arañas (MAMMOLA et al., 2017). Es por eso que mucho de lo que se dice de estos arácnidos están basadas en pareceres y en datos no siempre de origen certero. 
Según la Real Academia Española (RAE, 2019) un mito en su cuarta acepción se refiere a "Persona o cosa a la que se atribuyen cualidades o excelencias que no tiene". Las arañas y los escorpiones son un claro ejemplo de cualidades que la gente les ha otorgado y que no tienen. Por ejemplo, algunas personas creen erróneamente que las arañas son insectos y la mayoría las incluye en la vaga categoría de "bichos". Otra creencia es que los escorpiones y los alacranes son entidades diferentes (DE ARMAS, 2001), sin embargo, la palabra alacrán viene del árabe al-ágrab y quiere decir escorpión. La palabra escorpión viene del latín scorpio, omis y quiere decir alacrán. El nombre científico del orden es Scorpiones. Estos animales formaron parte de muchas de las supersticiones de los pueblos y han influenciado la imaginación de los habitantes de Oriente y del Mediterráneo desde épocas remotas. Aparecen en la mitología desde las actividades del Dios de Persia, Mithras, como enviados del diablo. Desde entonces los escorpiones quedaron asociados a todo aquello que representara el mal en cada una de las diferentes culturas. Incluso el Talmud y la Biblia hacen referencia a los escorpiones como animales repugnantes y formidables a la vez. Una interesante recopilación de cómo se trató a las arañas y a los alacranes a lo largo de la historia de la humanidad ha sido llevada a cabo por Hoffman (1993).

Muchas de estas creencias van tomando diferentes formas según el momento histórico en el que se analice la cultura. Todas las creencias en torno a los arácnidos estuvieron siempre circunscriptas a lo mítico, nada de lo propuesto pudo ser respaldado científicamente, con el agregado de que los avances científicos han ido demostrando que las creencias acerca de los arácnidos son falsas en su mayoría. Sin embargo, a pesar de la difusión que dieron los investigadores y los encargados de divulgación científica en distintos medios sobre estos descubrimientos, el poder de convencimiento de la población ha sido casi insignificante. Quizá esto sea debido a alguna impronta innata que hay en el ser humano (HOEL et al., 2017).

Según Davis \& Pless (2001), al evento de sufrir daño ocasionado por un arácnido se lo debería definir como lesión o injuria y no como accidente (como comúnmente se lo conoce). En Argentina, las lesiones producidas por picaduras de arañas o de escorpiones son de notificación obligatoria del grupo C, según la ley 15.465 de Argentina (SENASA, 2017) y son monitoreadas a nivel nacional por el Sistema Nacional de Vigilancia de la Salud dependiente de la Secretaría de Salud de la Nación. Argentina tuvo 8.436 denuncias por picaduras de escorpiones en 
2016 y 9.146 en 2015, en tanto que de arañas se registraron 978 y 1.231 picaduras, respectivamente (MINISTERIO..., 2019).

Otros animales, como los insectos dermápteros son confundidos con escorpiones y se los considera como potencial peligro para el ser humano (ROSA ALCÁZAR et al., 2009). Sobre la base de lo expuesto, el objetivo del presente trabajo fue conocer mediante una encuesta, cuáles son los conocimientos de las personas sobre arácnidos (arañas y escorpiones) y poner a prueba mitos y verdades sobre ellos mediante preguntas y repreguntas y evaluar si estos conocimientos tienen incidencia en la salud.

\section{Material y Métodos}

Para evaluar el conocimiento de la población sobre mitos y verdades de los arácnidos se diseńó y se llevó a cabo una encuesta desde junio de 2013 a julio de 2017 en soporte digital y en papel. Ésta fue completada desde internet o mediante planillas, las que luego se volcaron en una base de datos. La encuesta contenía datos personales a completar, como edad, sexo, estudios alcanzados, y si tenían o no conocimientos previos sobre arañas y escorpiones. Conjuntamente debían responder preguntas puntuales basadas en imágenes de insectos (Dermaptera, Coleoptera) y de arácnidos (Opiliones: Phalangiidae, Gonyleptidae; Escorpiones: Bothriurus bonariensis, Tityus trivittatus; Arañas: Loxosceles laeta, Latrodectus sp., Pholcus phalangioides, y Acanthoscurria sp.), donde debían contestar si el ejemplar mostrado era peligroso o no para el ser humano, o si no sabían. Finalmente la encuesta contenía 28 sentencias referidas a mitos o verdades que tenían como eje una aseveración que el encuestado debía contestar "verdadero, falso o no sé” (figura 1). 
Figura 1. Modelo de encuesta ¿Qué sabe usted de arácnidos?

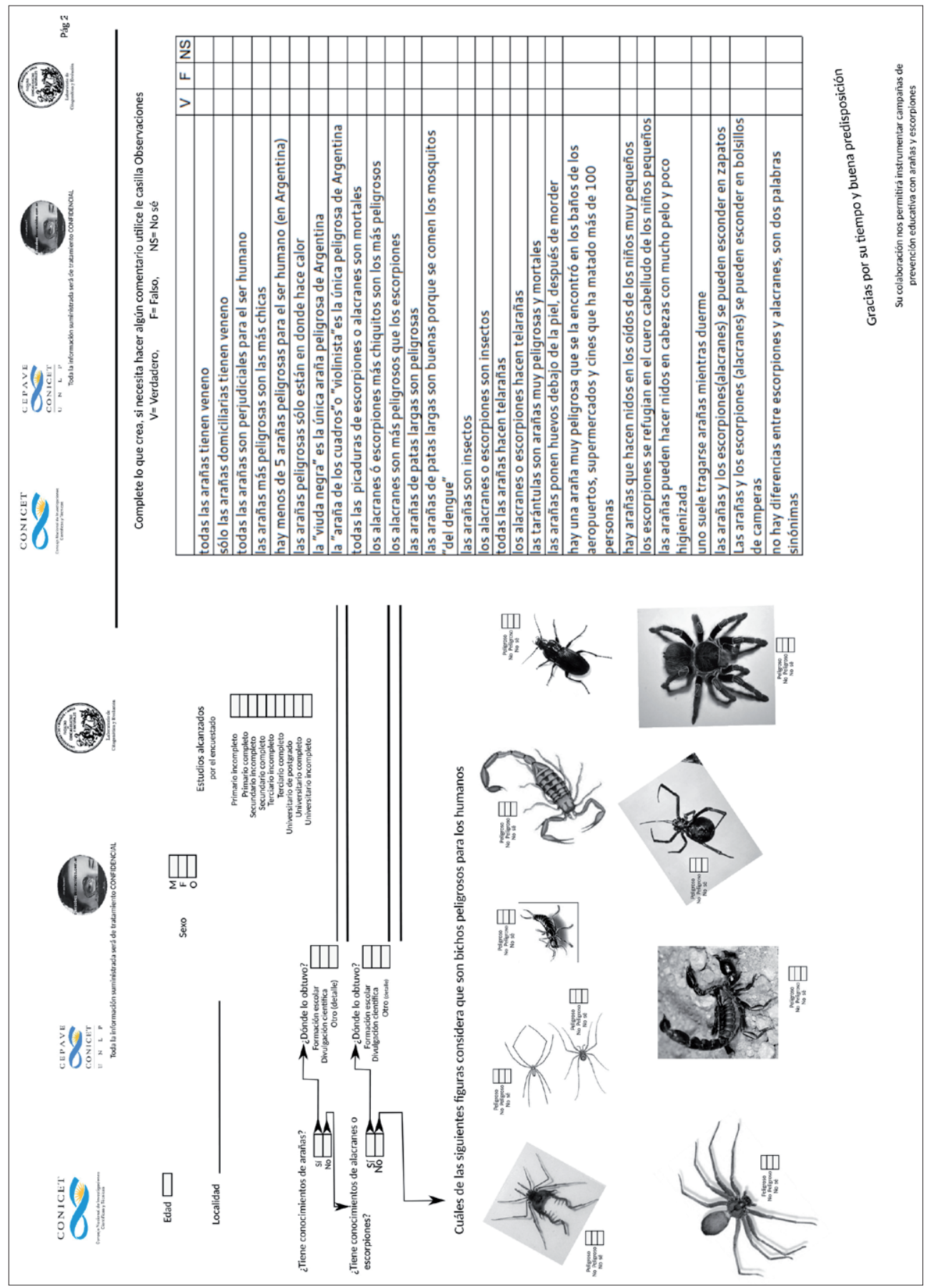


El diseño de la muestra fue de tipo no probabilística casual (SAMPIERI et al., 2003). Realizar una encuesta de tipo probabilístico significaba una erogación económica que estaba fuera de nuestro alcance. Muestras casuales son aquellas que suelen tomarse sin ningún criterio previo significativo. Se reservó el dominio quesabesdearacnidos.com.ar y se diseñó en Joomla una página con la información. La encuesta se acopló desde Google Drive como formulario asociado a una planilla de cálculo. Luego de un semestre de prueba privada se hizo pública y se le dio difusión por diferentes medios. Para difundir y dar visibilidad a la propuesta, se participó en 1.400 notas periodísticas que abordaron el tema de araneismo y escorpionismo, publicadas en diferentes portales digitales, con copia en las redes sociales Facebook y Twitter. También se utilizó el espacio de diferentes entrevistas de prevención de picaduras y promoción de salud y se enviaron mensajes electrónicos a diferentes foros de discusión. ${ }^{1}$

Las respuestas totales y por sexo de cada participante, se consideraron como si fuera un examen, utilizando la siguiente escala: Insuficiente los que contestaron hasta 3 bien, Regular a los que respondieron entre 4 y 5 de manera correcta, Bien los que lo hicieron con 6 y 7 y Muy Bien para los que contestaron de manera correcta 8 o más. Los datos obtenidos fueron analizados a través pruebas de Chi cuadrado.

\section{Resultados}

En los 37 meses que estuvo activa la encuesta, participaron 1.593 personas, de las cuales $52,67 \%(n=839)$ fueron mujeres, $46,89 \%(n=747)$ varones, y $0,44 \%$ se identificaron como otros. Esta población estuvo compuesta mayoritariamente por personas con estudios avanzados, siendo la mayoría estudiantes universitarios (26,87\%) y en segundo lugar universitarios con estudios incompletos (25,30\%) (tabla 1). El grupo que participó osciló entre los 12 a 81 años; con una media de 37,28 \pm 13,33 años; siendo mayoritaria la participación (60,51\%) entre 20 y 40 años (tabla 2). 
Tabla 1. Distribución por nivel de estudios de las personas que participaron de la encuesta ¿Qué sabe usted de arácnidos?

\begin{tabular}{|l|c|c|}
\hline \multicolumn{1}{|c|}{ Nivel de estudios alcanzados } & Total & $\%$ \\
\hline Primaria completa & 25 & 1,57 \\
\hline Primaria incompleta & 4 & 0,25 \\
\hline Secundario completo & 172 & 10,80 \\
\hline Secundario incompleto & 62 & 3,89 \\
\hline Terciario completo & 199 & 12,49 \\
\hline Terciario incompleto & 106 & 6,65 \\
\hline Universitario completo & 403 & 25,30 \\
\hline Universitario incompleto & 428 & 26,87 \\
\hline Universitario postgrado (completo) & 194 & 12,18 \\
\hline Total & 1.593 & 100 \\
\hline
\end{tabular}

Tabla 2. Distribución por edades de las personas que participaron de la encuesta ¿Qué sabe usted de arácnidos?

\begin{tabular}{|c|c|c|}
\hline Edad & Total & $\%$ \\
\hline$<=40$ & 266 & 16,70 \\
\hline$<=25$ & 244 & 15,32 \\
\hline$<=35$ & 234 & 14,69 \\
\hline$<=30$ & 220 & 13,81 \\
\hline$<=45$ & 185 & 11,61 \\
\hline$<=50$ & 108 & 6,78 \\
\hline$<=55$ & 86 & 5,40 \\
\hline$<=18$ & 77 & 4,83 \\
\hline$<=60$ & 77 & 4,83 \\
\hline$<=65$ & 48 & 3,01 \\
\hline$<=70$ & 31 & 1,95 \\
\hline$>=71$ & 17 & 1,07 \\
\hline Total & 1.593 & 100 \\
\hline
\end{tabular}

La provincia de Buenos Aires fue la que tuvo mayor participación con 28,19\%, seguida por la Ciudad Autónoma de Buenos Aires con 22,54\%, Córdoba con 10,30\% y Santa Fe con 6,15\%, el resto de las provincias aportó menos del 5,00\%. No se recibieron participaciones de la provincia de Formosa. Países limítrofes y otros países aportaron $12,18 \%$ de las respuestas (tabla 3). 
Tabla 3. Respuesta por distritos de las personas que participaron de la encuesta ¿Qué sabe usted de arácnidos?

\begin{tabular}{|c|c|c|}
\hline Distrito (Provincia/País) & Total & $\%$ \\
\hline Catamarca & 1 & 0,06 \\
\hline La Pampa & 4 & 0,25 \\
\hline Tierra del Fuego & 4 & 0,25 \\
\hline San Luis & 7 & 0,44 \\
\hline Países limítrofes (Uruguay, Brasil Paraguay, Bolivia o Chile) & 8 & 0,50 \\
\hline Santa Cruz & 9 & 0,56 \\
\hline Chaco & 10 & 0,63 \\
\hline Santiago del Estero & 11 & 0,69 \\
\hline La Rioja & 13 & 0,82 \\
\hline Corrientes & 14 & 0,88 \\
\hline San Juan & 16 & 1,00 \\
\hline Jujuy & 20 & 1,26 \\
\hline Chubut & 21 & 1,32 \\
\hline Outro País & 32 & 2,01 \\
\hline Misiones & 38 & 2,39 \\
\hline Tucumán & 38 & 2,39 \\
\hline Neuquén & 40 & 2,51 \\
\hline Entre Ríos & 41 & 2,57 \\
\hline Salta & 46 & 2,89 \\
\hline Mendoza & 72 & 4,52 \\
\hline Río Negro & 78 & 4,90 \\
\hline Santa Fe & 98 & 6,15 \\
\hline Córdoba & 164 & 10,30 \\
\hline Ciudad Autónoma de Buenos Aires & 359 & 22,54 \\
\hline Buenos Aires (Provincia) & 449 & 28,19 \\
\hline Total & 1.593 & 100 \\
\hline
\end{tabular}

Del total de participantes, $41,80 \%$ dijo tener conocimientos sobre arañas, compuesto por $7,47 \%$ que dijo que esos conocimientos los obtuvieron de la formación escolar, 18,08\% de programas de divulgación científica y 16,26\% de otras fuentes. Respecto al saber sobre escorpiones 39,68\% manifestó tener conocimiento, compuesto por 5,11\% que dijo que la instrucción la obtuvo de la formación escolar, $17,78 \%$ de programas de divulgación científica y $16,38 \%$ de otras fuentes.

Las diferencias entre los que afirmaban saber de arañas y los que decían saber de escorpiones no fueron significativas, arrojando un Valor Estadístico de 1,50; y $\chi 2_{(1 ; 0,005)}=3,84$. 


\section{Análisis de las respuestas sobre las figuras de artrópodos (insectos y arácnidos)}

Del análisis de las respuestas referidas a la peligrosidad de los diez artrópodos mostrados mediante imágenes en la encuesta, solo 38 varones y 12 mujeres respondieron bien las diez; siendo la diferencia en la respuesta entre sexos significativa (Valor Estadístico: 17,$\left.81 ; \chi 2_{(1 ; 0,005)}=3,84\right)$. Cometieron un solo error en las respuestas 709 varones, 827 mujeres y siete de otro género y contestaron "No sé" en todos los ítems 11 participantes (2 varones y 9 mujeres). Ningún encuestado contestó los 10 casos mal. El resto de las respuestas fue variable respecto a los errores.

$\mathrm{Al}$ analizar las respuestas de cada participante en las imágenes como si fuera un examen, los valores fueron: Insuficiente 771 (varones: 281; mujeres 490), Regular 445 (232; 213), Bueno 247 (147; 100), Muy Bueno 123 (87; 36). De estos valores, la diferencia en las respuestas entre varones y mujeres es significativa (Valor estadístico: 82,$\left.49 ; \chi 2_{(3 ; 0,005)}=7,82\right)$.

Al comparar la forma en la que respondieron los que dicen tener conocimientos y la población total que participó, se observa que las respuestas tienen proporciones distintas que difieren estadísticamente, excepto para Tityus, Loxosceles y Latrodectus, donde las diferencias son no significativas.

Figura 2. Distribución de respuestas ante las imágenes de artrópodos por las personas que participaron de la encuesta ¿Qué sabe usted de arácnidos?

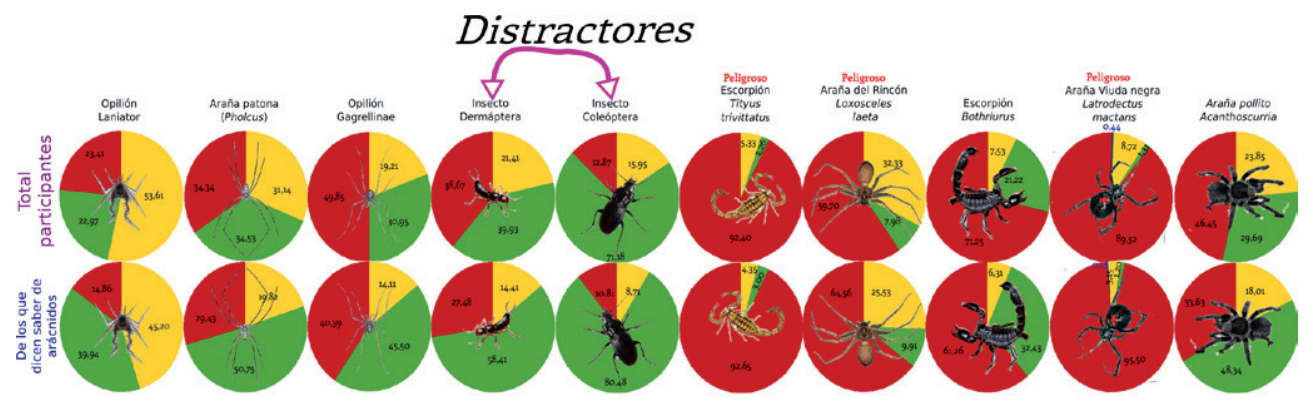

\section{Análisis de las imágenes referidas a arañas}

$\mathrm{Al}$ analizar las imágenes de arańas, solo 178 participantes (118 varones, 59 mujeres y uno de otro género) manifestaron que Loxosceles laeta y Latrodectus sp., eran especies peligrosas para el ser humano y que Pholcus phalangioides y Acanthoscurria 
sp. no lo eran. Las diferencias en las respuestas, al comparar el desempeño de ambos sexos, arrojan resultados con diferencias que son significativas (Valor estadístico: $\left.30,65 \times 2_{(2 ; 0,005)}=5,99\right)$. (figura 2$)$

\section{Análisis de las imágenes referidas a escorpiones}

Al analizar las imágenes de escorpiones, 326 personas (191 varones, 133 mujeres y dos de otro género) contestaron que Tityus trivittatus era una especie peligrosa para el ser humano y Bothriurus bonariensis no. Las diferencias en las respuestas por sexos, arrojan resultados con diferencias significativas (Valor estadístico:

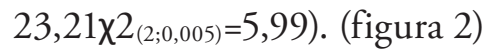

\section{Análisis de las sentencias en general}

Al evaluar las sentencias, se observó que el mismo concepto cuando se lo relaciona en distintas preguntas, generó en el mismo participante algunas respuestas ilógicas, como cuando se afirmó que "El alacrán es más peligroso que el escorpión" y que el "El alacrán y el escorpión son lo mismo". De las 816 personas que contestaron que el alacrán es más peligroso que el escorpión, 477 dijeron que alacrán y escorpión son lo mismo. Del análisis de ambas respuestas se puede razonar que los que contestaron que el alacrán no es más peligroso que el escorpión lo podrían estar manifestando porque son lo mismo, lo que justificaría el falso de la primera opción. De los 154 que contestan que el alacrán es más peligroso que el escorpión, 110 afirman que escorpión y alacrán son entidades diferentes y 12 dicen que no saben si son lo mismo o no, de donde se puede deducir que la mayoría de los que dijeron que era verdadera la primera opción lo hizo por creer que son animales diferentes. Al evaluar a los que contestaron como falso que el alacrán es más peligroso que el escorpión y se lo cruza con que también contestaron que es falso que el alacrán y el escorpión son lo mismo, se llega a que 283 participantes consideran que el escorpión es más peligroso que el alacrán por ser diferentes entidades.

$\mathrm{Al}$ agrupar a los que dijeron que el alacrán es más peligroso que el escorpión (154 participantes) con los que dijeron no saber si lo eran (622), y de ellos seleccionar a los que dijeron que era falso que el escorpión y el alacrán son lo mismo, se puede contabilizar que hay 613 personas que también consideran que el alacrán y el escorpión son entidades diferentes. Este número sumado al 283 anterior demuestra que 896 encuestados $(56,24 \%$ del total) consideran que son entidades diferentes. Cuando se 
analiza "si todas las arañas tienen veneno", solo 28,27\% dijo que sí y 89,20\% de los participantes contestaron que no "todas las arañas son perjudiciales para el ser humano". Al evaluar el tamaño y la peligrosidad, 44,22\% de los participantes consideran que las más peligrosas son las más pequeñas. A pesar de que es la minoría (si se contrasta contra los que afirman que es verdad junto a los que no saben), ese valor es demasiado alto.

Cuando se evalúa el mito "las arañas peligrosas están donde hace calor", 55,28\% considera que la afirmación es falsa. La mayoría de las personas reconocen que la viuda negra (Latrodectus sp.) y la araña violinista (Loxosceles sp.) no son las únicas arañas peligrosas (tabla 4).

Tabla 4. Distribución de respuestas a las sentencias de las personas que participaron de la encuesta ¿Qué sabe usted de arácnidos? (casillas grisadas: respuestas esperadas como correctas; letras en negrita respuestas que fueron seleccionadas como mayoritarias por los participantes (por no alcanzar un valor estadísticamente analizable, no se incorpora"otro sexo")

\begin{tabular}{|c|c|c|c|}
\hline & V & $\mathbf{F}$ & NS \\
\hline Todas las arańas tienen veneno & 28,27 & 62,94 & 8,79 \\
\hline Sólo las arañas domiciliarias tienen veneno & 2,64 & 87,63 & 9,74 \\
\hline Todas las arańas son perjudiciales para el ser humano & 4,08 & 89,20 & 6,72 \\
\hline Las arañas más peligrosas son las más chicas & 28,33 & 44,22 & 27,45 \\
\hline Hay menos de 5 arańas peligrosas para el ser humano (en Argentina) & 0,41 & 0,13 & 46,55 \\
\hline Las arańas peligrosas sólo están en donde hace calor & 8,04 & 55,28 & 36,68 \\
\hline La "viuda negra" es la única arańa peligrosa de Argentina & 6,78 & 70,04 & 23,18 \\
\hline La “arańa de los cuadros" o "violinista” es la única peligrosa de Argentina & 3,64 & 63,51 & 32,85 \\
\hline Todas las picaduras de escorpiones o alacranes son mortales & 5,72 & 81,60 & 12,69 \\
\hline Los alacranes ó escorpiones más chiquitos son los más peligrosos & 19,28 & 38,63 & 42,09 \\
\hline Los alacranes son más peligrosos que los escorpiones & 9,67 & 51,26 & 39,07 \\
\hline Las arańas de patas largas son peligrosas & 10,68 & 55,84 & 31,60 \\
\hline Las arańas de patas largas son buenas porque se comen los mosquitos "del dengue" & 22,55 & 30,84 & 46,61 \\
\hline Las arañas son insectos & 24,06 & 67,84 & 8,10 \\
\hline Los alacranes o escorpiones son insectos & 21,48 & 66,58 & 11,93 \\
\hline Todas las arañas hacen telarañas & 32,66 & 39,01 & 28,33 \\
\hline Los alacranes o escorpiones hacen telarańas & 1,19 & 84,67 & 14,13 \\
\hline Las tarántulas son arañas muy peligrosas y mortales & 23,56 & 56,47 & 19,97 \\
\hline Las arańas ponen huevos debajo de la piel, después de morder & 3,89 & 64,26 & 31,85 \\
\hline $\begin{array}{l}\text { Hay una arańa muy peligrosa que se la encontró en los bańos de los aeropuertos, } \\
\text { supermercados y cines que ha matado más de } 100 \text { personas }\end{array}$ & 6,97 & 34,05 & 58,98 \\
\hline Hay arãnas que hacen nidos en los oídos de los niños muy pequeños & 5,97 & 51,01 & 43,03 \\
\hline Los escorpiones se refugian en el cuero cabelludo de los niños pequeńos & 1,13 & 76,82 & 22,05 \\
\hline Las arańas pueden hacer nidos en cabezas con mucho pelo y poco higienizada & 8,73 & 57,79 & 33,48 \\
\hline Uno suele tragarse arańas mientras duerme & 12,25 & 58,92 & 28,83 \\
\hline Las arańas y los escorpiones (alacranes) se pueden esconder en zapatos & 92,34 & 1,88 & 5,78 \\
\hline Las arańas y los escorpiones (alacranes) se pueden esconder en bolsillos de camperas & 64,26 & 14,20 & 21,55 \\
\hline No hay diferencias entre escorpiones y alacranes, son dos palabras sinónimas & 40,20 & 37,44 & 22,36 \\
\hline
\end{tabular}




\section{Conclusiones y Discusión}

Si bien la encuesta estuvo activa 37 meses se pudo contar con un número de participantes que permite realizar una primera aproximación al conocimiento general que se tiene acerca de los arácnidos, particularmente de ciertos temores y prejuicios. Ambos sexos estuvieron representados de manera similar y la distribución por edades fue la esperada, con una mayor presencia de personas que son socialmente activas. Según el Censo Nacional de Población, Hogares y Viviendas 2010 de Argentina, (INDEC, 2010), la población cuenta con $0,16 \%$ de personas con nivel universitario incompleto y $1,13 \%$ con nivel universitario completo, estos datos se alejan de manera significativa de la distribución poblacional encuestada, hecho esperable desde el momento que se optó por el sistema de recolección de datos no probabilístico. Sin embargo, los resultados son de importancia para tener una primera aproximación a los saberes generales y origen de los mismos.

La mayor participación provino de personas de provincias que tienen las ciudades más numerosas del país, cuatro de los distritos más representados en las encuestas figuran entre los cinco que tienen el mayor índice de inscriptos a universidades y ofertas universitarias (Anuario de Estadisticas Universitarias - Argentina 2013). La alta participación de este grupo de personas sería la causal del alto nivel educativo de los mismos. Cabe destacar una gran cantidad de respuestas incorrectas en relación con el alto nivel de estudio de los participantes.

Las personas que dicen saber del tema no muestran diferencias significativas en las respuestas con respecto a aquellas que dicen no saber, por lo que habría que averiguar, en futuras investigaciones, si las personas que dicen saber de arácnidos, en realidad tienen conocimientos del tema o sólo es una autovaloración equivocada de su propio conocimiento. Una posible respuesta se puede empezar a esbozar a partir de que el porcentaje que diferenció de manera correcta a los escorpiones peligrosos y no peligrosos, fue de $20,46 \%$, cuando $39,68 \%$ dijo saber de escorpiones y lo mismo se observa al diferenciar arañas peligrosas de no peligrosas, lo pueden hacer $11,17 \%$, cuando 41,80\% dijeron saber de arañas.

Ya sea en arañas o escorpiones, cualquiera de los dos grupos de personas, los que dicen saber y los que dicen no saber del tema, presentan importantes errores conceptuales con respecto a la peligrosidad de los animales. Dentro de los arácnidos, es notoria la cantidad de participantes que dice saber de arácnidos y a su vez indica como peligrosos 
o desconoce la peligrosidad de animales que son inofensivos como los opiliones (60\% para Phalangiidae y 54,50\% para Gonyleptidae). En el mismo sentido, consideran peligrosos insectos que no lo son, como el caso de los dermápteros y coleópteros, que fueron simples distractores sin ser arácnidos. Algunas personas consideran a los dermápteros como peligrosos, por su comportamiento similar al de los escorpiones o bien por otras falsas creencias, como por ejemplo "que depositan huevos en el cerebro y cortan el tímpano” (DEL VAL DE GORTARI, 2013, OPAS, 1962).

$\mathrm{Al}$ analizar un promedio de los porcentajes de aciertos en las respuestas acerca de las creencias populares, considerando si se han declarado mujer o varón, el promedio de aciertos es $61,77 \% \pm 18,05$ para varones y $56,43 \% \pm 19,27$ para mujeres. Al realizar el mismo análisis con los errores, varones arroja $14,63 \% \pm 13,37$, en tanto que mujeres $14,35 \% \pm 14,90$. Esta diferencia en aciertos según sexo del participante, se invierte en el caso del "no sabe". Al realizar el mismo análisis, considerando los aciertos en función del sexo declarado, pero con las imágenes (10 artrópodos), la relación fue 38 (varones)/12 (mujeres)=3,166; cuando se evaluó lo mismo para las respuestas exclusivas de arańas la proporción se redujo a 118/59=2, y cuando se evaluó solo escorpiones, la proporción se achicó aún más, 191/133=1,4. Si se considera la participación total varones $747 / 839$ mujeres la relación arroja 0,89 , muy lejano a la relación de aciertos por sexo. De aquí se puede concluir que ambos sexos tienen diferente reacción según la imagen a la que se exponen. Estos resultados son acordes con los obtenidos por Tucker \& Bond (1997), quienes encontraron correlación significativa entre las participantes femeninas y el miedo a los animales, en tanto que esa correlación no fue significativa entre los participantes masculinos.

A los escorpiones de la especie Tityus trivittatus se lo reconoce junto con la araña Latrodectus sp. (Viuda Negra) como peligrosos por la mayoría de los participantes $(92,40 \%$ y $89,52 \%$ respectivamente). Es importante que además de esta identificación, también se observe un alto reconocimiento de los diferentes sitios donde se pueden esconder estos animales. Es llamativo que la mayoría de los participantes dicen que los escorpiones y los alacranes son entidades diferentes, el riesgo de esto es que se minimice una picadura por aceptar esta separación y asignar a uno peligrosidad y al otro no.

Excepto el caso de Acanthoscurria sp. (Mygalomorphae) en el resto de los dilemas no aparecen diferencias entre los preconceptos de aquellos que no se reconocen conocedores de arácnidos con los que sí se reconocen. 
Pese a la importancia que la gente le da a los arácnidos en la vida diaria, los resultados de esta encuesta muestran que es más lo que se ignora que lo que se sabe del grupo; y que muchos de los conocimientos que se tiene, están más sostenidos desde las noticias que se escuchan, se leen o pasan de boca en boca, que de los conocimientos empíricos generados por medios académicos. En este sentido los resultados concuerdan con los propuestos por otros autores en los que descubrieron que la información falsa o "fake news" tienen mayor aceptación que aquellas noticias producidas desde espacios académicos (LAZER et al., 2018; TEMMING, 2018; HAMBRICK; MARQUARDT, 2018; McCLAIN, 2017; MARTÍN, 2019). En algunos casos, especialmente en los mitos, se puede ver una fuerte aceptación de los dichos sin evaluar si es posible con los propios conocimientos que se tienen de los seres vivos.

Al vincular el alto nivel educativo de los participantes, y el cúmulo de errores encontrados nos conduce a generar la hipótesis de que es posible que el refuerzo constante de los mitos pueda estar dado desde los sectores muy instruidos e influyentes en la educación, dado que son muchas de estas personas formadas, las que capacitarán a otras, desde sus conocimientos. Es sabido que algunas creencias consideradas propias de una época han tenido su centro de difusión y reafirmación desde las clases consideradas más intelectuales, este es el caso de la teoría de la generación espontánea (hoy considerada un mito) descripta por Aristóteles en la antigüedad y después sostenida por otros grandes pensadores y científicos como Descartes, Bacon o Newton y si bien Pasteur demostró lo erróneo de esta teoría, la creencia siguió entre las clases populares bien entrado el siglo XX como un mito bajo la mirada del nuevo saber (GRATZER, 2005).

Cuando un falso saber se encuentra asociado a repulsión o temor, como el que generan los arácnidos, ese falso conocimiento es mucho más difícil de eliminar de las personas, hecho que no pasa cuando el mito no está acompañado de un refuerzo negativo casi permanente, como pudo suceder con el caso antes citado de la generación espontánea. En este sentido, Rosa Alcázar et al. (2009) propone un trabajo que permite abandonar las fobias primero y en una segunda instancia, derrumbar las falsas creencias.

Los resultados obtenidos revisten importancia, especialmente para las personas que coordinan áreas de salud, ya que, por la formación declarada por los participantes de la encuesta, muchos de ellos podrían ser formadores de referentes de salud y ser 
parte de las campañas de prevención de picaduras. A los datos anteriores se suma que cuando se analizan los mitos, se observa que es alto el número de personas que cree en ellos, independientemente del caso que se analice. La creencia en falsas verdades es una falencia importante que habría que buscar minimizar, generando bibliografía editada de manera responsable, que no señale, por ejemplo, que los escorpiones y los alacranes son animales diferentes (DIFERENCIAS.EU, 2018) o invitando a los comunicadores de ciencia a que no informen que los escorpiones y las arañas son insectos ${ }^{2}$ y que den a conocer las especies de importancia sanitaria y datos sobre su biología y hábitat.

Resulta contradictorio que la mayoría de los participantes opinen que no todas las arañas tienen veneno y que no todas son peligrosas para el ser humano, sin embargo existe una aversión generalizada contra ellas; esta doble percepción no tiene coherencia. Sin embargo, cuando se muestran imágenes de arañas, se contestaría desde el temor y no desde el discurso que sostienen respecto a que no todas tienen veneno, ergo no serían peligrosas. De aquí se podría inferir que cuando el animal está presente (o la imagen del mismo) genera un tipo de respuesta, quizás más impulsiva o irracional que cuando no se muestra y en este caso la respuesta es más reflexiva.

Conocer con más detalle la fauna que nos rodea, puede ser un camino para que las personas le pierdan el miedo a todo aquel artrópodo que no conozcan. Por ejemplo, se observa que numerosas personas han reconocido peligro en seres que no los tienen y que ni siquiera son arácnidos. También hay ejemplos de conocimientos que se oponen a la lógica adquirida en la formación académica, como creer en mitos que colocan a algunos arácnidos en situaciones en los que nunca pudieron haber sido vistos o que hubieran sido leídas en algún cuento como por ejemplo que "viven en el pelo" (OCAMPO, 1959).

Los resultados que se desprenden de este trabajo nos obligan a pensar en políticas de educación que tengan por objeto revertir el conocimiento erróneo sobre estos arácnidos, y lograr que estos artrópodos sean vistos como un grupo más de los tantos que existen. De este modo, quizá, se puedan cambiar conocimientos basados en los prejuicios o información de dudosa veracidad, por aquellos basados en la evidencia científica que permitan un manejo más racional y así poder brindar medidas de prevención eficientes y pautas de acción si ocurriese un accidente. Para comenzar a recorrer este camino sería necesario trabajar con las fobias a estos animales tal como sugieren De Jong et al., (1997), Rosa Alcázar (2009) y Öst (1996). ${ }^{3}$ 


\section{Agradecimientos}

A todas las personas que participaron de la encuesta. A las instituciones que de diferentes formas apoyaron la iniciativa. A los distintos medios que permitieron la difusión de la misma para que llegase a la mayor cantidad posible de gente. A Iván Luiz Fiorini de Magalhaes, por la traducción del resumen al portugués, y a Manuela Reboredo, al inglés.

\section{Referencias}

20MINUTOS. Dos arañas, una viva y otra muerta: la causa del dolor de oído de este niño. 2007. Disponible en: <http:/www.20minutos.es/noticia/231212/0/aracnido/dolor/oido/\#xtor=AD$15 \& x t s=467263>$ Acceso en: 15 mayo 2019.

ALBIR, S. Arañas en el pelo. 2016. Disponible en: <https://www.archerphoto.eu/esmentira/ aranas-en-el-pelo/> Acceso en: 15 mayo 2019.

ALF. Arañas peligrosas y no tanto. 2009. Disponible en: <http://miraloquemeencontreintern eteando.blogspot.com.ar/2009/06/hace-poco-reenvie-un-correo-en-el-cual.html> Acceso en: 15 mayo 2019.

ANUARIO DE ESTADÍSTICAS UNIVERSITARIAS. Ministerio de Educación. - Argentina 2013. Disponible en: <http://informacionpresupuestaria.siu.edu.ar/DocumentosSPU/ Anuario_2013.pdf> Acceso en: 15 mayo 2019.

BLACKLEDGE, T. A. Spider Silk: Molecular Structure and Function in Webs. En: NENTWIG, W. (Ed). Spider Ecophysiology: Berlín: Springer-Verlag Berlin Heidelberg, 2013. DOI 10.1007/978-3-642-33989-9_20.

BLANCO VARGAS, E.; SALAS LÓPEZ, G. Arácnidos: Guía de Campo. Bogotá, Colombia: Bichos, 2007.

CASANOVA, J. Araña Telamonia de dos rayas causa la muerte por poseer veneno de alta toxicidad. 2009. Disponible en: <http://lacolumnadecaricuaosalud.blogspot.com.ar/2009/07/aranatelamonia-de-dos-rayas-causa-la.html> Acceso en: 15 mayo 2019.

DARWIN, C. Naturalist's Voyage Round the World. The Voyage of The Beagle. En: MURRAY, J. Journal of Researches into the Natural History and Geology of the Countries Visited During the Voyage Round the World of H.M.S. Beagle Under the Command of Captain Fitz Roy: R.N. Londres, Albermarle Street, 1913. Disponible en: <http://www.gutenberg.org/files/3704/3704h/3704-h.htm> Acceso en: 15 mayo 2019.

DAVIS, R.; PLESS, B. Accidents are not unpredictable. BMJ 322. 2001. Disponible en: <https:// doi.org/10.1136/bmj.322.7298.1320> Acceso en: 15 mayo 2019. 
DE ARMAS, L. F. El alacrán en la cultura cubana contemporánea. Una aproximación. Revista Ibérica de Aracnología, n. 4, p. 99-103, 2001. Disponible en: <http://entomologia.rediris.es/ aracnet/9/etnobiologia/alacran.htm> Acceso en: 15 mayo 2019.

DE JONG, P. J.; ANDREA, H.; MURIS, P. Spider phobia in children: disgust and fear before and after treatment. Behaviour Reserarch and Therapy, v. 35, n. 6, p. 559-562. 1997. Disponible en: <https://doi.org/10.1016/S0005-7967(97)00002-8> Acceso en 15 de mayo 2019

DE LA COLINA, J. Realidad, mito y poesía del alacrán. 2012. Disponible en: <https://www. letraslibres.com/mexico-espana/realidad-mito-y-poesia-del-alacran> Acceso en: 15 mayo 2019.

DEL VAL DE GORTARI, E. Que las tijerillas se meten a los oídos de los humanos? Universidad Nacional Autónoma de México, Campus Moreli. 2013. Disponible en: <http://www.morelia. unam.mx/vinculacion/index.php?option=com_content\&view=article\&id=275:que-las-tijerillasse-meten-a-los-oidos-de-los-humanos\&catid=5:general\&Itemid=29> Acceso en: 15 mayo 2019.

DIFERENCIAS.EU. Diferencias entre alacrán y escorpión. 2018. Disponible en: <https:// diferencias.eu/entre-alacran-y-escorpion/> Acceso en: 15 mayo 2019.

EL NUEVE.COM. Fue al hospital por un dolor de cabeza y le sacan una araña viva del oído. 2017. Disponible en: <https://www.elnueve.com/video-fue-al-hospital-por-un-dolor-de-cabezay-le-sacan-una-arana-viva-del-oido> Acceso en: 15 mayo 2019.

ESPINOSA ARANZALES, A. F. et al. Caso sospechoso de envenenamiento por araña reclusa (Loxosceles) y revisión de la literatura, 2014 Disponible en: <http://repository. urosario.edu.co/bitstream/handle/10336/5688/RoncancioZuniga-GinaPaola-2014. pdf?sequence=1\&isAllowed $=y>$ Acceso en: 15 mayo 2019 .

FERNÁNDEZ RUBIO, F. El impacto de los arácnidos sobre la mente humana. Argutorio, v. 40, p. 85-95, 2018.

GRATZER, W. Eurekas y Euforias. Cómo entender la ciencia a través de sus anécdotas. Barcelona. Editorial Crítica. 2005.

HAMBRICK, D. Z.; MARQUARDT, M. Cognitive ability and vulnerability to fake. Scientific American. 2018. Disponible en: <https://www.scientificamerican.com/article/cognitive-abilityand-vulnerability-to-fake-news/> Acceso en: 15 mayo 2019.

HOELH, S. et al. Itsy Bitsy Spider...: Infants React with Increased Arousal to Spiders and Snakes. Frontiers in Psychology, v. 8, p. 1710, 2017 DOI: 10.3389/fpsyg.2017.01710. Disponible en: <https://www.ncbi.nlm.nih.gov/pmc/articles/PMC5651927/pdf/fpsyg-08-01710.pdf> Acceso en: 15 mayo 2019.

HOFFMAN, A. El maravilloso mundo de las arañas. Fondo de Cultura Económica, S.A. de C.V., México DF 1993. Disponible en: <http://bibliotecadigital.ilce.edu.mx/sites/ciencia/volumen3/ ciencia3/116/html/aracnido.html> Acceso en: 15 mayo 2019. 
INSTITUTO NACIONAL DE ESTADÍSTICA Y CENSOS. Censo Nacional de Población, Hogares y Viviendas. Total de país. 2010. Disponible en: <https://www.indec.gov.ar/nivel4_ default.asp?id_tema_1=2\&id_tema_2=41\&id_tema_3=135> Acceso en: 15 mayo 2019.

INFOBAE. Una mujer tuvo una araña en el oído 5 dias. 2012. Disponible en: <https://www. infobae.com/2012/08/11/1056086-una-mujer-tuvo-una-arana-el-oido-5-dias/> Acceso en: 15 mayo 2019.

LAS PROVINCIAS.ES. Una araña anida en el oído de una mujer durante cinco días. 2012. Disponible en: <http:/www.lasprovincias.es/20120811/mas-actualidad/sociedad/arana-anidaoido-mujer-201208111206.html> Acceso en: 15 mayo 2019.

LAZER, D. M. J. et al. The science of fake news. Science, v. 359, n. 6380, p. 1094-1096, 2018. DOI: $10.1126 /$ science.aao2998.

MAMMOLA, S.; MICHALIK, P.; HEBETS, E. A.; ISAIA, M. Record breaking achievements by spiders and the scientists who study them. Peer J., v. 5, ,p. e3972, 2017. DOI 10.7717/ peerj.3972.

MARTIN, B. Las personas que rechazan el consenso científico tienen una percepción exagerada de su propia comprensión. El País, Madrid, 2019. Disponible en: <https://elpais.com/ elpais/2019/01/16/ciencia/1547638949_673010.html> Acceso en 19 mayo 2019.

MCCLAIN, C. R. Practices and promises of Facebook for science outreach: Becoming a "Nerd of Trust”. PlosBiology. 2017 Disponible en: <https://doi.org/10.1371/journal.pbio.2002020> Acceso en: 15 mayo 2019.

MINISTERIO DE SALUD Y DESARROLLO SOCIAL. Boletín Integrado De Vigilancia. Buenos Aires. 2019. Disponible en: <https://www.argentina.gob.ar/salud/epidemiologia/ boletinesepidemiologicos> Acceso en: 15 mayo 2019.

MONTEFIORE, A. ¿Araña asesina en los inodoros? 2010. Disponible en: <https:// periodicotribuna.com.ar/7399-arana-asesina-en-los-inodoros.html>Acceso en: 15 mayo 2019.

MUNCHIES. Cómo cocinar insectos: escorpiones, 2015. Disponible en: <https://munchies.vice. com/es/article/kbx5z9/como-cocinar-insectos-escorpiones> Acceso en: 15 mayo 2019.

MUNDO INFINITO. Diferencias entre escorpión y alacrán. 2019. Disponible en: <https:// elmundoinfinito.com/diferencia-escorpion-alacran/>. Acceso en: 15 mayo 2019.

OCAMPO, S. La boda. En: . La furia y otros cuentos. Buenos Aires: Editorial Sur, 1959.

ORGANIZACIÓN PANAMERICANA DE LASALUD. Introducción al estudio de los artrópodos de importancia en Salud Pública. Washington,DC: PAHO, 1962. Publicaciones científicas; 69:1-32. Disponible en: <http://iris.paho.org/xmlui/bitstream/handle/123456789/1352/41751. pdf> Acceso en: 15 mayo 2019. 
OVE REIN, J. The Scorpion files. 2019. Disponible en: <https://www.ntnu.no/ub/scorpionfiles/> Acceso en: 15 mayo 2019.

ÖST, L. One-Session Group Treatment Of Spider Phobia. Behaviour and Research Therapy, v. 34, n. 9, p. 707-715, 1996 Disponible en: <https://doi.org/10.1016/0005-7967(96)00022-8> Acceso en: 15 mayo 2019.

PERSPECTIVA SUR. Advierten sobre nuevas apariciones de escorpiones en Bernal, 2018. Disponible en: <http://www.perspectivasur.com/3/76840-advierten-sobre-nuevas-aparicionesde-escorpiones-en-bernal> Acceso en: 15 mayo 2019.

PICADURAS Y MORDEDURAS. Diferencia entre alacrán y escorpión ¿̨son el mismo animal los alacranes y los escorpiones? 2015. Disponible en: <http://www.picaduras.info/diferenciaentre-alacran-y-escorpion/> Acceso en: 15 mayo 2019.

RAE. Diccionario de la lengua española.Madrid, 2019. Disponible en: <http://dle.rae. es/?id=PQM1Wus> Acceso en: 15 mayo 2019.

ROSA ALCÁZAR, A. I.; ORGILÉS AMORÓS, M.; MÉNDEZ CARRILLO, X. Una revisión cuantitativa de los tratamientos psicológicos en las fobias a las serpientes y arañas en niños y adolescentes. Revista Electrónica de Motivación y Emoción, v. 6, n. 13, p. 1-12, 2009. Disponible en: <http://reme.uji.es/articulos/arosaa5580505103/> Acceso en: 15 mayo 2019.

SAMPIERI, R. H.; COLLADO, C. F.; BAPTISTA LUCIO, P. Metodología de la investigación. México DF: McGraw-Hill Interamericana; 2003.

SENASA. Ley Nacional-15465-1960-Poder Ejecutivo Nacional. Buenos Aires. Disponible en: <http://www.senasa.gob.ar/normativas/ley-nacional-15465-1960-poder-ejecutivo-nacional> Acceso en: 15 mayo 2019.

TEMMING, M. People are bad at spotting fake news. Can computer programs do better? Science News Magazine, v. 194, n. 3, p. 22, 2018. Disponible en: <https://www.sciencenews.org/ article/can-computer-programs-flag-fake-news> Acceso en: 15 mayo 2019.

TUCKER, M.; BOND, N. W. The roles of gender, sex role, and disgust in fear of animals. Personality and Individual Differences, v. 22, n. 1, p. 135-138, 1997. Disponible en: <https://doi. org/10.1016/S0191-8869(96)00168-7> Acceso en: 15 mayo 2019.

UNO TV.COM. La mejor forma de sacar a una araña del oído. 2015. Disponible en: <https:// www.unotv.com/noticias/portal/entretenimiento/detalle/la-mejor-forma-de-sacar-a-una-aranadel-oido-812077/> Acceso en: 15 mayo 2019.

VÍQUEZ, C. Mitos y Creencias. Revista Entomología.net. 2003. Disponible en: <http:// entomologia.net/mitos.htm> Acceso en: 15 mayo 2019. 
WORLD SPIDER CATALOG. World Spider Catalog. Version 20.0. 2019 Disponible en: <http://wsc.nmbe.ch> DOI: 10.24436/2. Acceso en: 15 mayo 2019.

YAHOO Noticias. Una araña anida durante días en el oído de una mujer. 2012 Disponible en: <https://es-us.noticias.yahoo.com/blogs/ciencia-curiosa/una-ara\%C3\%B1a-anida-duranted\%C3\%ADas-en-el-o\%C3\%ADdo-de-una-mujer.html> Acceso en: 15 mayo 2019.

\section{Notas}

${ }^{1}$ Finalizado el estudio, en agosto de 2017 se desactivó la reserva del sitio, sin embargo se puede acceder para ver cómo se presentó la información en <https://web.archive.org/web/20160404020803/http://quesabesdearacnidos.com.ar/>

${ }^{2}$ Mundo Infinito (2019), Espinosa Aranzales et al. (2014), Perspectiva Sur (2018), Munchies (2015), Picaduras y mordeduras (2015), por solo citar algunos ejemplos que a diario aparecen en los medios de comunicación.

${ }^{3}$ S. G. Rodríguez Gil y C. L. Scioscia: conceptualización, investigación, metodología, escritura del borrador, revisión y edición. L Giambelluca: investigación, metodología, manejo de software, validación de resultados, escritura del borrador, revisión y edición. G. Reboredo: investigación, visualización de la encuesta, escritura del borrador, revisión y edición. A. González: conceptualización, análisis formal, investigación, metodología, supervision, validación, visualización de la encuesta, escritura del borrador, revisión y edición. 


\section{Resumo}

\section{Avaliação do conhecimento de mitos e verdades sobre aracnideos na Argentina e sua possivel incidência na saúde}

Os aracnídeos são um grupo megadiverso, que inclui aranhas e escorpiôes. Embora todas as espécies de ambos os grupos tenham veneno, só algumas são perigosas para o ser humano, podendo causar até a morte, e ocupam lugar importante nas tradições de muitas cidades. $\mathrm{O}$ objetivo do presente trabalho é conhecer, através de uma pesquisa, quais são os conhecimentos das pessoas sobre aranhas e escorpióes, e testar mitos e verdades por meio de perguntas e perguntas cruzadas. Os resultados mostram considerável desconhecimento por parte da população participante, em especial aquela com nível avançado de educação, que acredita em mitos mais frequentemente do que nas verdadeiras descobertas científicas; além disso, a resposta entre homens e mulheres difere significativamente em muitas questóes. Esses resultados nos levam a pensar em políticas educacionais que revertam esses conhecimentos errôneos baseados em preconceitos ou informaçóes de veracidade duvidosa, para aqueles baseados em evidências científicas. Isso permitiria um manejo racional dessas espécies, possibilitando medidas de prevenção eficientes e diretrizes para ação caso ocorra um acidente.

> Palavras-chave: araneísmo; escorpionismo; conhecimento; saúde. 


\section{Abstract}

Assessment of knowledge of myths and truths

about arachnids in Argentina and their possible impact on health

Arachnids are a megadiverse group, that include spiders and scorpions. Although the species of both groups are poisonous, only a few are dangerous to human beings, having the potential of causing death, and have an important place in the traditions of many cultures. This work aimed to evaluate, by means of a survey, the knowledge of the public about spiders and scorpions, and to test myths and truths through questions and cross-examinations. Results show a significant lack of awareness among the participants, especially those with higher level of education, who accept myths over true scientific discoveries; besides answers to many questions differ significantly between men and women. These results require the development of education policies that replace such erroneous knowledge based on prejudices or information of doubtful veracity, for scientific facts. This would allow a rational management of these species and thus provide efficient preventive measures and guidelines in case of accidents.

Keywords: araneism; scorpionism; knowledgement; health. 